\title{
METOO: THE IMPACT OF RAPE CULTURE IN THE MEDIA, MEENAKSHI GIGI DURHAM. (2021)
}

Cambridge: Polity Press, 191pp.,

ISBN 978-1-509-53519-4, hbk, \$103.95

ISBN 978-1-509-53520-0, pbk, $\$ 32.95$

ISBN 978-1-509-53521-7, e/bk, from $\$ 18.00$

\section{Reviewed by Heather Anderson, Griffith University}

I write this review days after Bill Cosby was released from prison, his 2018 conviction for drugging and sexually assaulting a woman, 14 years earlier, overturned due to a legal technicality. The Australian music industry is still reeling from recent research suggesting 85 percent of women working in the sector have experienced sexual harassment. While not within the sphere of media industries, I also cannot ignore the scandals of sexual assault plaguing the Australian federal government. The importance and relevance of the \#MeToo movement could not have been more front and centre in my mind than when I began to read MeToo: The Impact of Rape Culture in the Media.

Gender and media scholar Meenakshi Gigi Durham has delivered a clearly written and confronting, yet engaging, text where she uses the media as a framework through which to discuss and analyse the international \#MeToo movement. This is relevant as media are central mechanisms, she argues, in the apparatus of sexual violence. News coverage, for example, reports on sexual assault itself, as well as societal responses and its accompanying commentary and political rhetoric. For those who are not directly affected by sexual violence, the media, in all its forms, plays a vital role in shaping our understandings. It is a site of rape representation, through both fictional and nonfictional accounts, that often silence and diminish the experiences of survivors and victims.

Durham's text unpacks the relationships between media, rape culture and \#MeToo through three distinct sections that outline the key strategies and structures of rape culture which normalise predatory behaviour within the media industries, protect perpetrators and limit the capacity of survivors to speak out about their experiences. The first section, 'Rapacity', discusses the media organisations and corporations at the epicentre of \#MeToo with the second, 'Representation', considering media content itself; how it incorporates and reinforces structures that consolidate rape culture while at other times resisting and exposing assault and harassment. There is an emphasis here on outlets based in the United States, however, this is to be expected. As Durham notes, activist Tarana Burke may have pioneered the phrase and the movement as early as 2006, but it was not until after a handful of American male media personalities (on and off the screen) were publicly outed as sexual predators that the \#MeToo movement gained global attention and influence. The dynamics of sexuality and gender in the media provide an analytical site through which we can consider the power systems that cultivate and allow for sexual assault, through the conduct and the output of media organisations.

Durham's final section 'Resistance' documents the broader backlash against \#MeToo, one which labels the movement as a feminist witch hunt. It explores rape myths and the grey areas that exist along the so-called continuum of sexual violence from coercion to violent assault. More importantly though, Durham provides an intersectional critique of the \#MeToo movement itself. While this section moves away from the role of media per se (as both a site 
of sexual violence and a supporter of \#MeToo), it nevertheless provides important commentary on the actual movement and its transition from a grassroots campaign driven by women of colour to an internationally recognised hashtag campaign. For example, Durham highlights the overtly carceral feminism of \#MeToo, that centres the criminal justice system as vital to its success. This is problematic for abolitionist activists who perceive misogyny, racism, homophobia and transphobia as inherent to the legal system and the prison industrial complex. Durham's inclusion of an abolitionist discourse is refreshing, as is the call for "an intersectional ethics for activism ... (that) draws on emerging visions of liberatory practices of justice..." (p.119).

MeToo: The Impact of Rape Culture in the Media provides an invaluable treatise of the \#MeToo Movement from a historical perspective that prioritises intersectional politics. Much still needs to be written about the role media (and media industries) can play to confront and dismantle rape culture in society, especially beyond the North American context. Durham's work is an excellent starting point, not only for media scholars but for anyone seeking to learn more about the \#MeToo movement.

https://orcid.org/0000-0002-4530-1435 